\title{
El culto a los animales sagrados emblemáticos en la cultura aymara de Chile
}

\author{
Maria Ester Grebe
}

\section{INTRODUCCIÓN}

El propósito de este trabajo es estudiar la continuidad y simbolismo del culto a ocho animales sagrados emblemáticos en la sociedad aymara de Chile. En la descripción de dicho culto se dará especial relevancia a las reactualizaciones rituales y sistema de creencias en cuyos contextos reaparecen los patrones cognitivo-simbólicos explícitos y subyacentes, ligados a los principios culturales dominantes del mundo andino. Ellos contribuyen a dar permanencia a la cultura andina regional y a identificar aquellos significados simbólicos de mayor gravitación y trascendencia.

Las representaciones de estos y otros animales -sobresaliendo entre ellos el motivo del felino (Dillehay, MS) - reaparecen con frecuencia en el arte prehispánico andino con amplia dispersión geográfica. En este sentido, se espera poder contribuir con orientaciones antropológicas y datos empíricos que faciliten la comprensión de sus respectivos ámbitos semánticos, símbolos y contextos culturales principales.

Sus materiales empíricos fueron recogidos por esta investigadora en trabajos de campo realizados a lo largo de las décadas de 1970 y 1980 en las aldeas pastoriles de Enquelga y Pisiga-Choque, pertenecientes a las mitades alta y baja de la comunidad altiplánica de Isluga (I Región).

\section{Resultados Empíricos}

\section{Los Animales Sagrados Emblemáticos de Isluga}

En el esquema cosmológico tripartito de los aymaras altiplánicos de Isluga se distinguen tres mundos estratificados verticalmente: 1) 
araj-pacha, el mundo superior de los cuerpos celestes; 2) taipi-pacha, el mundo intermedio de los hombres, de los espíritus de la montaña, de la tierra, y de la torre y nave de la iglesia católica que cobijan a las imágenes de los santos; y 3) manqha-pacha, el submundo de los animales silvestres, de los animales sagrados, y de Seren'-mallku, el espíritu del agua y de la música. Este estrato inferior del cosmos se considera desconocido y peligroso, relacionándose con el interior de la tierra, con las aguas y corrientes subterráneas. Se cree que allí se originó el nacimiento del reino animal (Grebe, 1980, pp. 156-174; 1981, pp. 69-73).

En el contexto de esta fauna silvestre subterránea se destacan ocho animales sagrados emblemáticos, cada uno de los cuales es objeto de culto y de una elaborada praxis ritual tradicional. Ellos son los siguientes: cóndor, águila, quirquincho (o armadillo), chullumpe (pájaro acuático), felino o gato montés (tite, suinave, suimaya o awatiri), sapo (jampato), lagarto (jarririnko) y serpiente (aserro). En la etnozoología aymara estos ocho a nimales sagrados son sallka, animales silvestres que "se aman". Esta expresión nativa significa que son objeto de veneración y culto por su naturaleza sagrada. En un nivel específico, se dividen en tres grupos, categorizándose de acuerdo a sus respectivas asociaciones con tres funciones productivas básicas del mundo andino (véase figura 1). Así, el felino y el pájaro chullumpe son emblemas del pastoreo; el cóndor, águila y quirquincho son emblemas de las reciprocidades e intercambios económicos, e inclusive de las actividades comerciales; y la serpiente, sapo y lagarto son emblemas de la agricultura. Mientras los primeros cinco animales sagrados se embalsaman -rellenándose su piel con lana de llama o alpaca- y se les vincula a los mallkus -espíritus de la montaña, dueños de toda la fauna silvestre-, los tres últimos animales sagrados se mantienen vivos o disecados - colocados en pequeñas cajas-y se les vincula a Sereno, el espíritu del agua y de la música, que reside en el mundo subterráneo (véanse fotos 1 a 7 ).

\section{FIG. 1: ETNOTAXONOMIA DE ANIMALES ANDINOS}

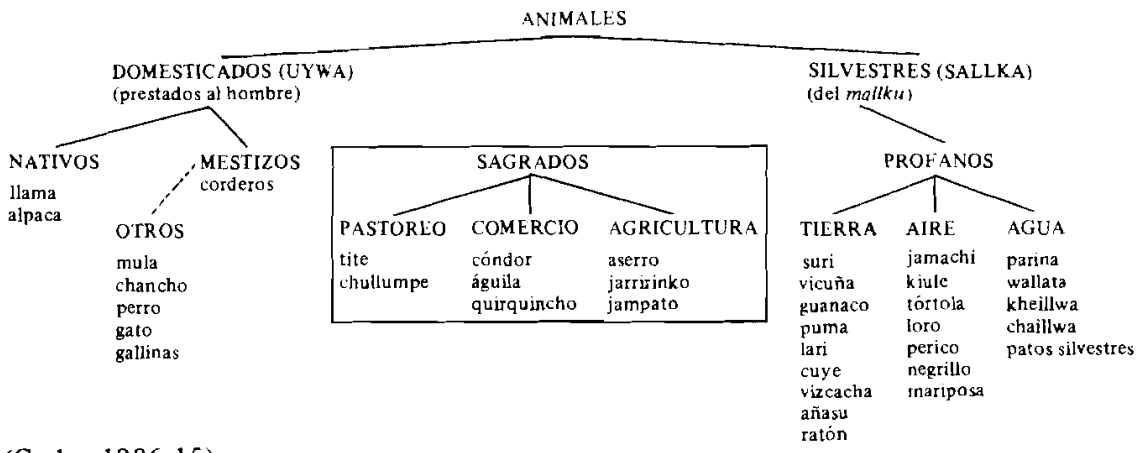

(Grebe, 1986:15) 


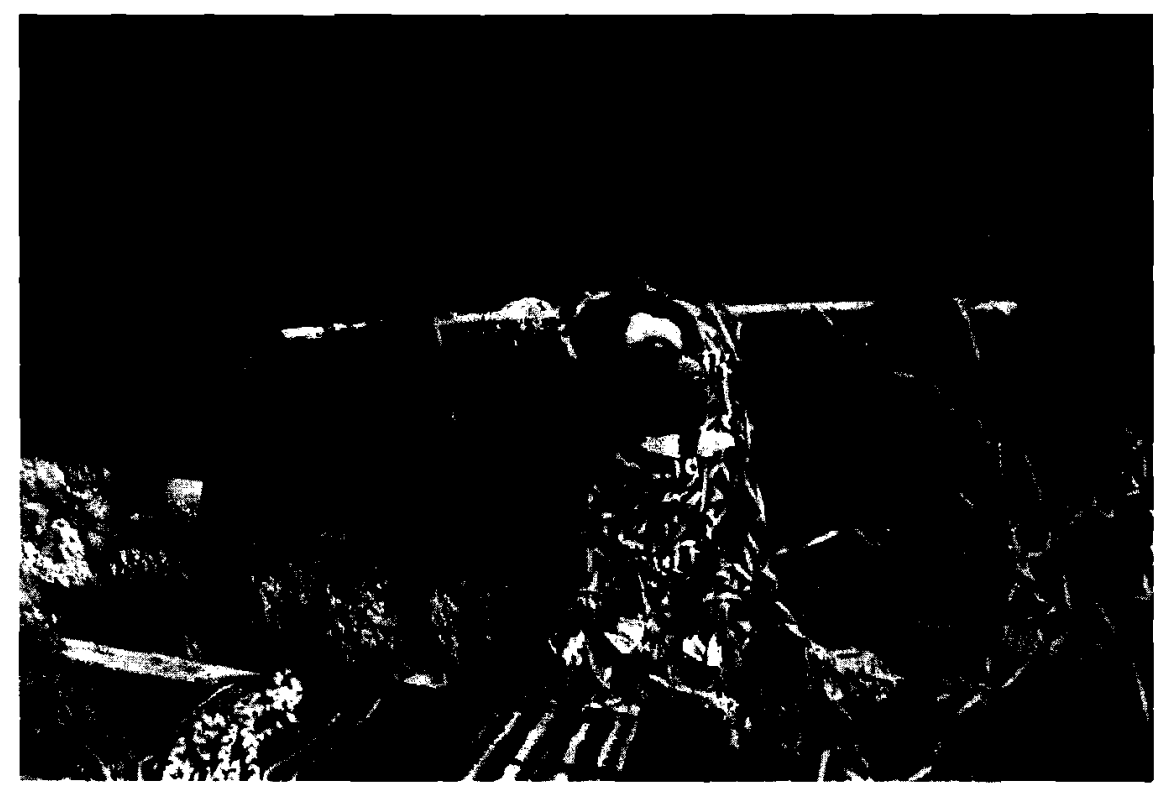

1. Cóndor.

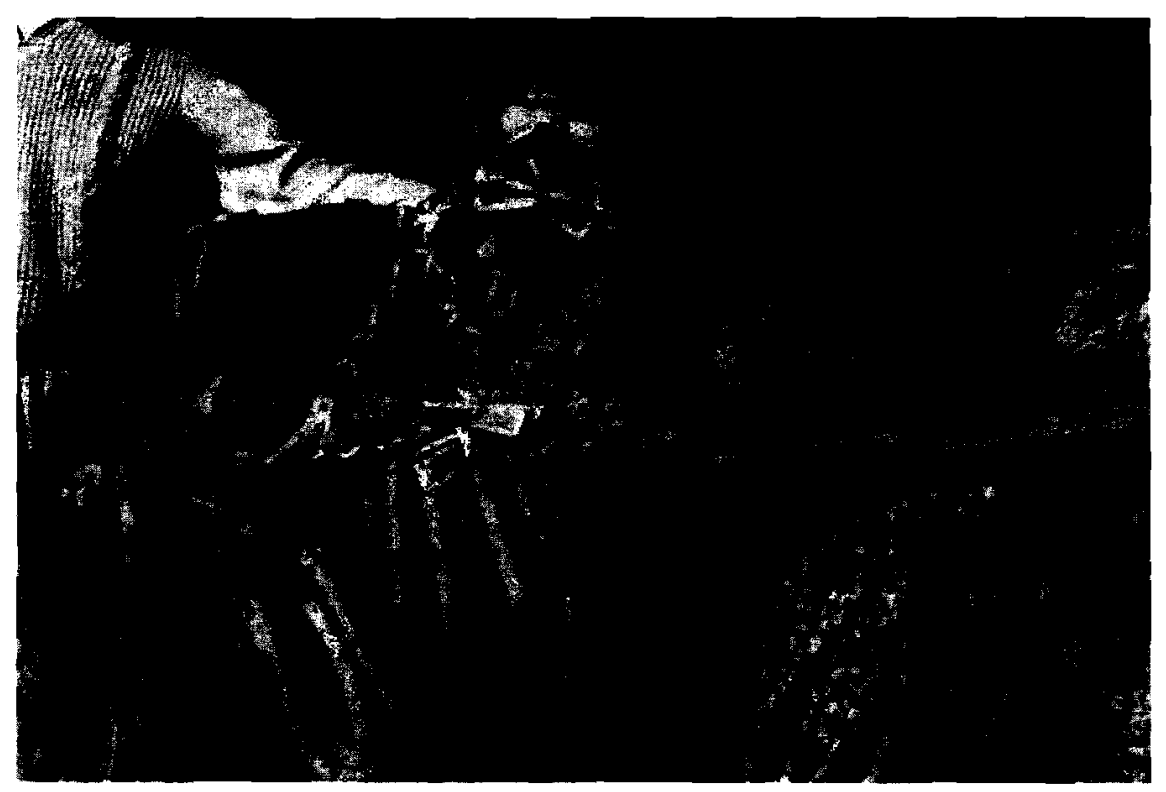

2. Aguila. 


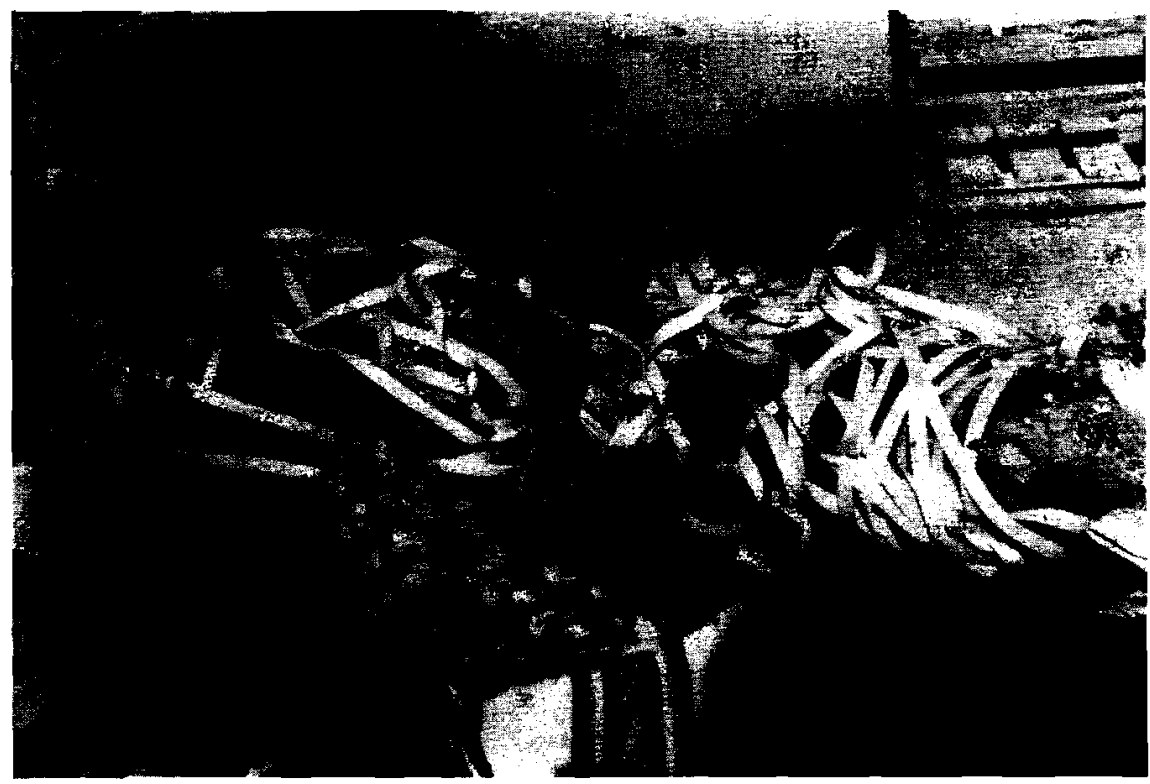

3.a. Quirquinchos.

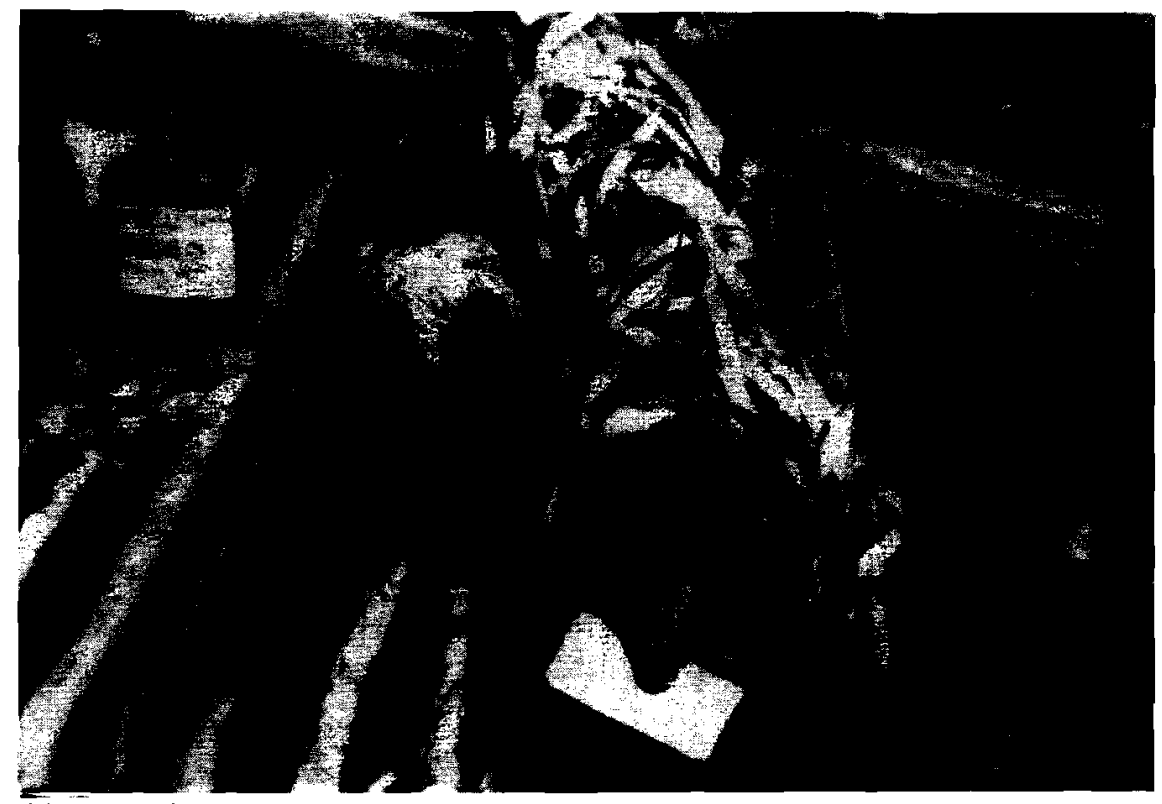

3.b. Quirquincho. 


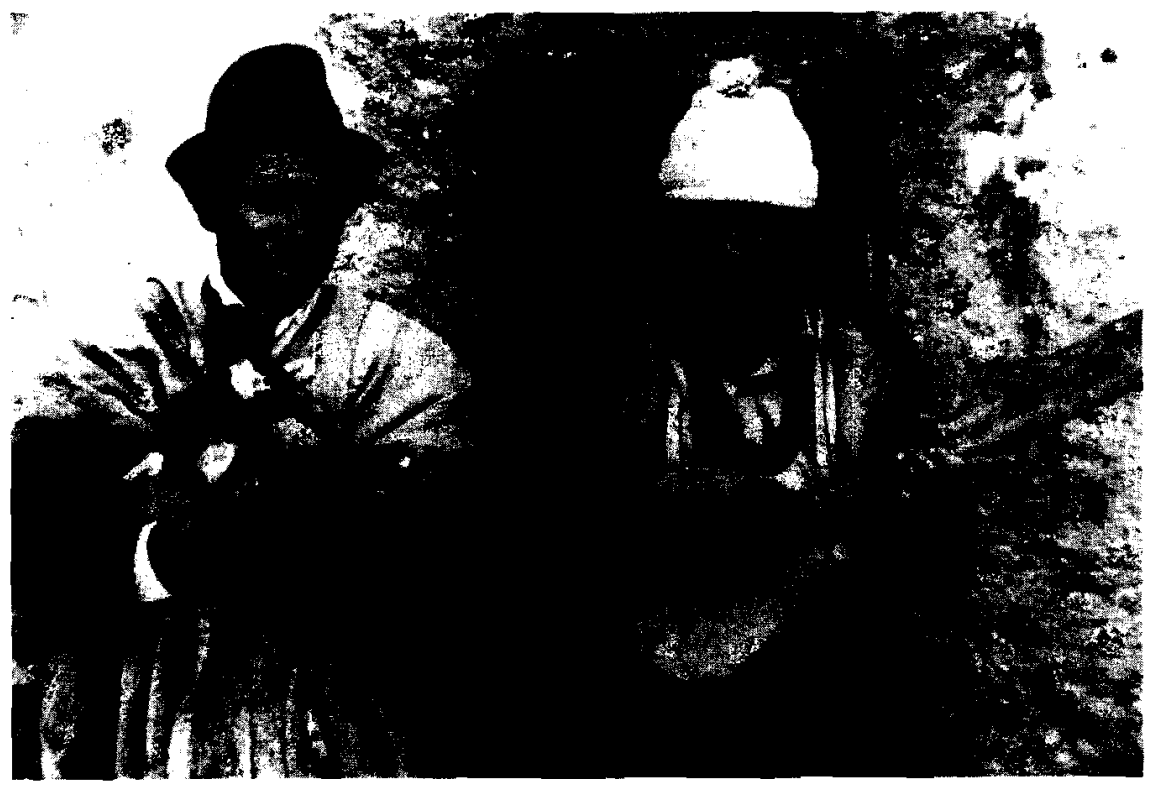

4. Chullumpe.

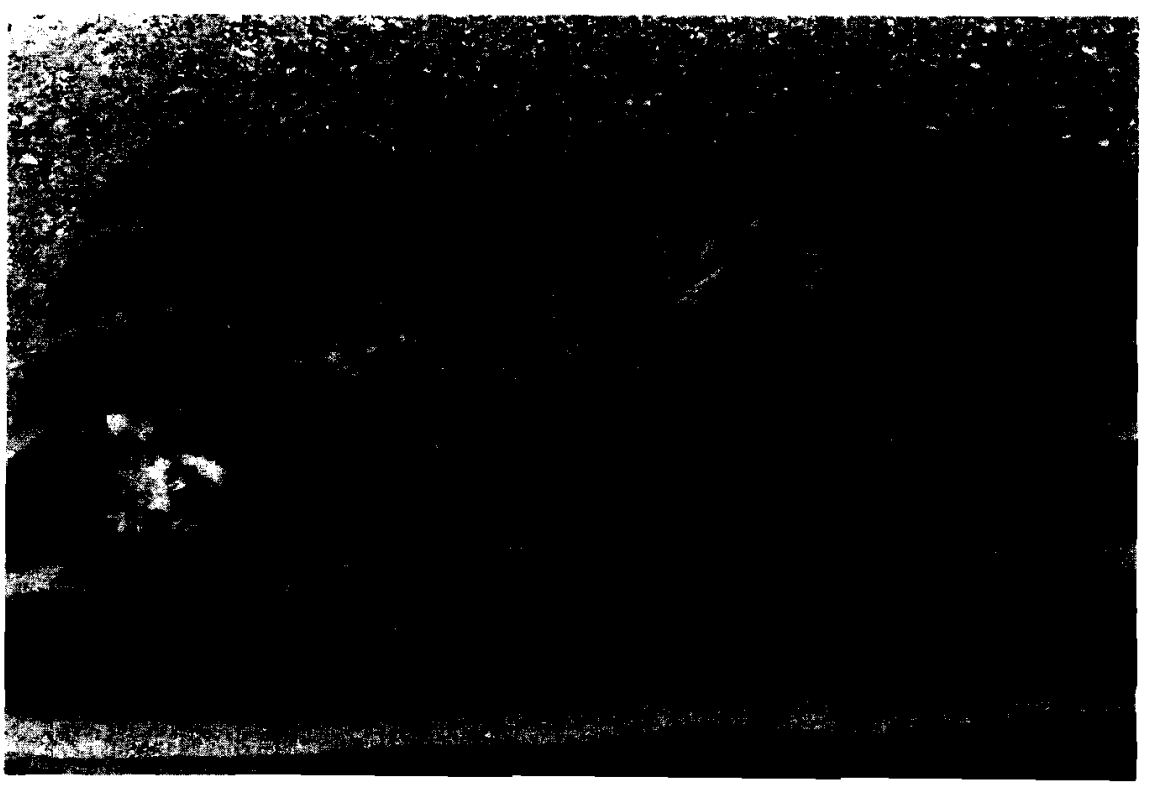

5. Felino. 


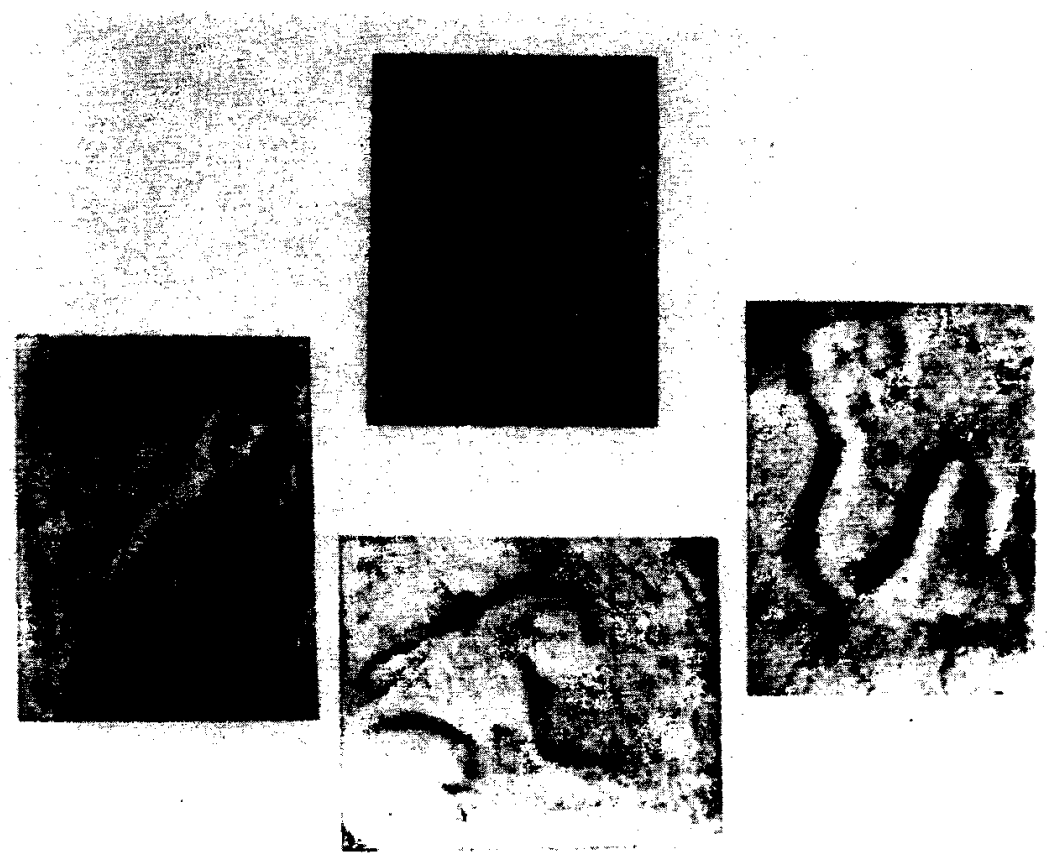

6. Serpiente, sapo, lagarto y Seren'mallku en posterior.

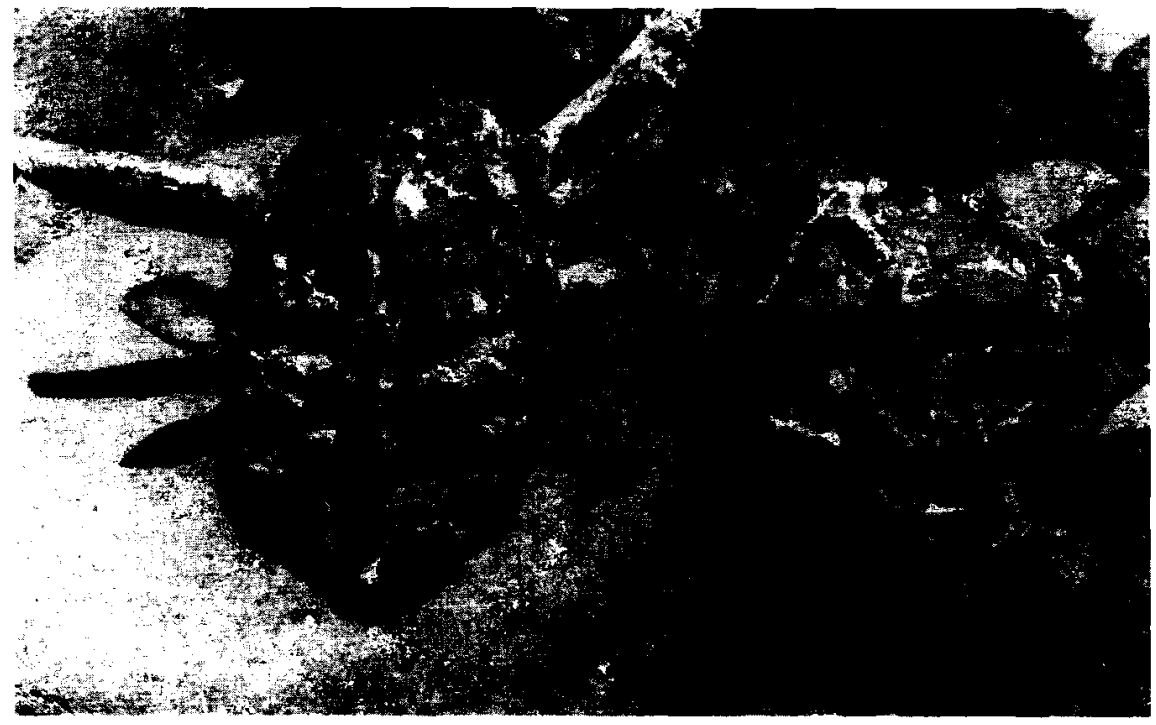

7. Máscaras con sapo, lagarto y serpiente. 


\section{Las Reactualizaciones rituales}

Los aymaras altiplánicos rinden culto a cada uno de los ocho animales sagrados emblemáticos del submundo aymara. Los ritos tradicionales correspondientes se dedican a los espíritus de la montaña y tierra (mallkus) y están a cargo de aquellos individuos que poseen uno o más de estos animales. Mediante estos ritos se valida y legitima la relación entre los mallkus y las actividades productivas, puesto que se cree que estos espíritus de la montaña y tierra son quienes controlan la producción agropecuaria y favorecen las reciprocidades que condicionan el bienestar de la comunidad. De este modo, los tres grupos de animales sagrados emblemáticos mediatizan esta relación, dándole permanencia y estabilidad a sus principios ideacionales básicos $\mathrm{y}$, a simismo, reforzando sus respectivos significados simbólicos.

Los ritos asociados a los animales sagrados emblemáticos ocurren en fechas o períodos determinados por el calendario anual. El culto general a los ocho animales sagrados tiene lugar el 10 de agosto y el 10 de enero de cada año; el culto al felino y al pájaro chullumpe tiene lugar en los ritos pastoriles de marcación de ganado durante los meses de enero y/o febrero; y el culto al cóndor, águila y quirquincho tiene lugar durante el último día del carnaval denominado Domingo de Tentación. Por su parte, el culto a la serpiente, lagarto y sapo parecen consistir en ceremonias privadas y secretas.

En general, estos ritos pueden ser privados o públicos, según cuenten con la participación del dueño del animal sagrado y de su familia nuclear, desarrollándose al interior de su vivienda; o bien con la participación del dueño, su familia extensa, parientes y amigos, desarrollándose al aire libre o al interior de alguna vivienda de la aldea pastoril.

Entre estos ritos se destacan aquellos destinados a la marcación del ganado -denominados enfloramientos o floreos-, los cuales son fuente excepcional de datos etnográficos sobre el culto a dos animales sagrados del pastor: el felino y el pájaro chullumpe. En Isluga se distinguen dos especies de este rito: la challta -rito simple semiprivado- y el huayño - rito complejo y público-. Mientras el primero dura un día, el segundo dura dos días. En ambos casos, cuando el dueño del ganado posee alguno de éstos animales sagrados, el centro de gravitación del ceremonial es la mesa, altar andino en cuyos costados se ubican un par de felinos o de pájaros chullumpes macho y hembra embalsamados (véase foto 8). Tanto la pareja de felinos como de pájaros chullumpes aparecen en los ritos de las mitades alta (araj-saya) y baja (manqha-saya) de la comunidad de Isluga, dependiendo del tipo de animales sagrados que posee el dueño del ganado. Por tanto, no es posible inferir su respectiva caracterización emblemática de las dos mitades que conforman la organización dual de la comunidad.

Los hallazgos de un trabajo etnográfico desarrollado en Enquelga (1983-1984), una aldea pastoril de la mitad alta de la comunidad de 


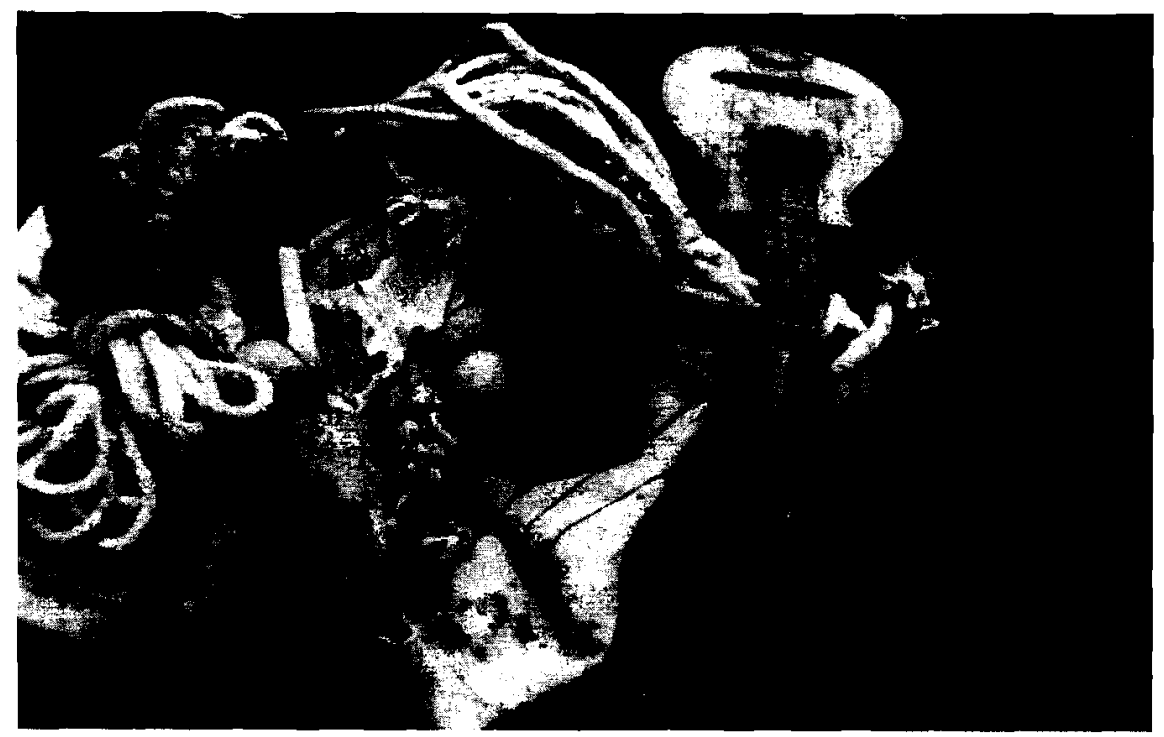

8. Mesa con felinos.

Isluga, indican que los pastores distinguen cuatro etapas en una challta (rito simple de marcación de ganado): 1) entrada, 2) vilancha, 3) floreo, y 4) boda o burra.

1) Entrada: En la vivienda del dueño del ganado se prepara un atado ritual colocando dentro de una giglia (manta tejida) los siguientes objetos: sogas o lazos del pastor; campanilla de bronce para el delantero -animal que guía el rebaño--; aretes, collares y lazadas de lanas multicolores para florear el ganado; alcohol pusi, coca y azúcar; incienso nativo (copala con $k$ 'olla); polvos minerales (sebario y limpe); vasijas ceremoniales; y un felino. El pastor y su esposa llevarán, respectivamente, al felino macho y hembra en sus propios atados. (En la comunidad baja de Isluga, el felino suele ser reemplazado por el pájaro chullumpe). Presidida por el pastor dueño del ganado -que lleva en su espalda el atado ritual principal-y por su esposa -que lleva el atado secundario-, la comitiva ritual se traslada al corral llevando diversos implementos rituales y alimentarios. Una vez en el corral, se instala la mesa sobre el suelo a la derecha de la entrada del corral. Sobre ella se coloca el contenido del atado ritual en distribución dual simétrica. Situados a ambos costados de esta mesa-altar, dos felinos presiden la ceremonia: el macho a la derecha y la hembra a la izquierda (compárese con Tschopik, 1951, p. 276; véase foto 9).

2) Vilancha: Junto a la mesa, se desarrolla la propiciación de los espíritus de la montaña (mallkus), de los cuales el felino es su símbolo mediatizador. Se procede a sacrificar un llamo macho blanco dentro del corral, complementado con sahumerios, aspersiones, libaciones y 


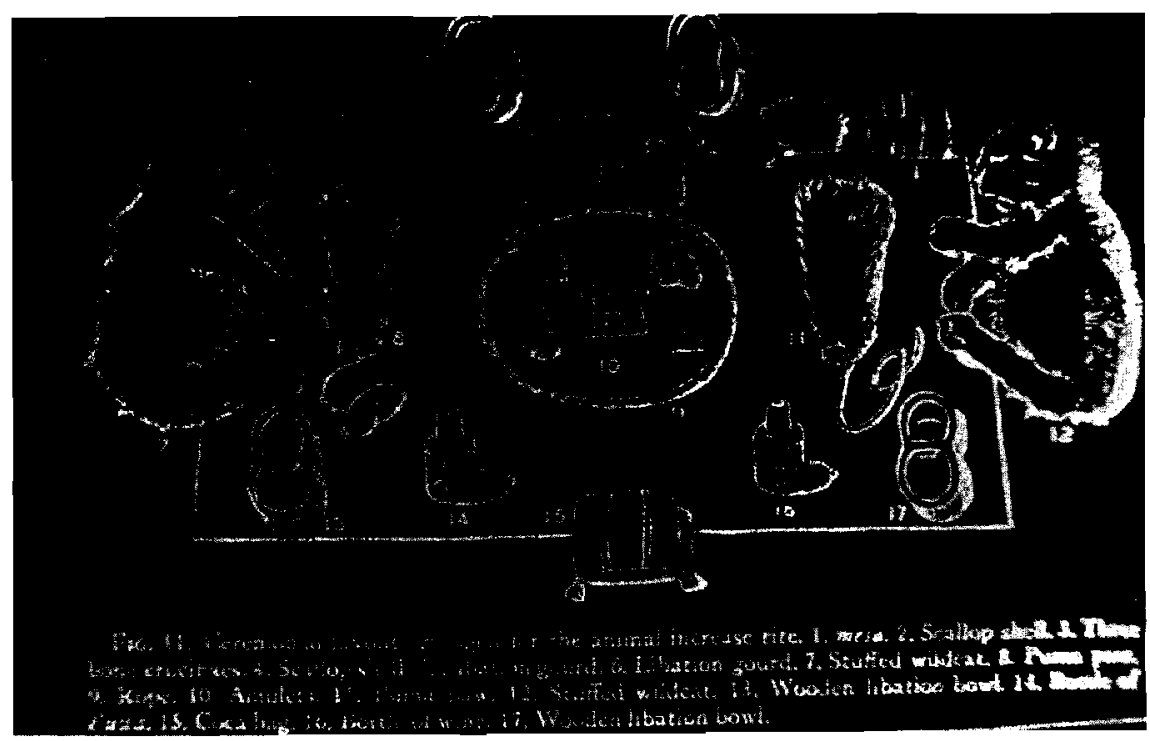

9. Lámina Tschopik.

movimientos circulares contra las manecillas del reloj de los oficiantes rituales. Mientras se faena este animal, se desarrolla la mesa de vilancha, colocándose sobre ella las patas del animal sacrificado. En esta mesa los animales sagrados son rodeados por los actores rituales sentados en círculo, reactualizándose así las tradicionales reciprocidades y redistribuciones propias de los principios dominantes del mundo andino (véase foto 10).

3) Floreo: Sobre el felino macho se colocan los adornos para florear el ganado, repartiéndose luego entre los participantes a cargo de esta tarea ritual. En una primera etapa se marcan todas las hembras de cuatro en cuatro; en la etapa siguiente, los machos en igual forma.

4) Boda o burra: La ceremonia concluye con una comida ritual de carácter solemne alrededor de la mesa, después de la cual la comitiva retorna a su aldea pastoril.

Durante todas las etapas de este ritual los dos felinos macho y hembra ocupan un lugar preferente en la mesa, siendo objeto de veneración religiosa. Cada uno de los participantes procede a salpicarlos con licor, coca y azúcar, agregando otras ofrendas e invocándolos en sus rogativas. (En la mitad baja de Isluga, el culto al pájaro chullumpe suele compartir las características recién descritas). En ambos casos la interpretación de canciones rituales dedicadas, y a sea al felino o al pájaro chullumpe proporcionan un canal de comunicación fecundo, a través del cual surgen contenidos relevantes para la comprensión del significado y simbolismo del rito. 


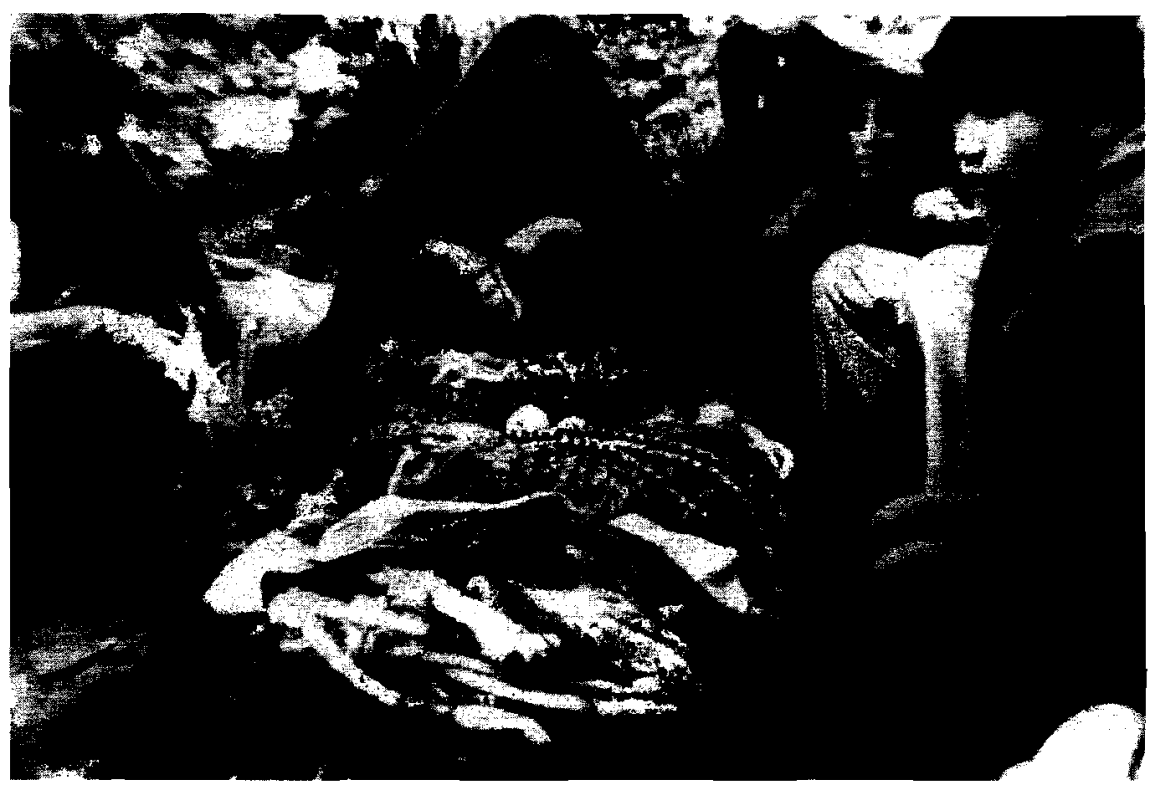

10. Mesa con felinos,

\section{Las Creencias y la Tradición Oral}

Las creencias y connotaciones simbólicas de los ocho animales sagrados de Isluga permiten comprender tanto el sentido y la función de la praxis ritual como su ámbito semántico. Los siguientes testimonios proporcionados por nuestros informantes condensan las concepciones compartidas al interior de la cultura aymara altiplánica de Chile:

1) Felino (tite, suinave, suimaya, awatiri): "Es awatiri del mallku (pastor del espíritu de la montaña). Cuida su ganado (de animales silvestres). Silba como pastor y los animales se mueven". Este testimonio se complementa con la siguiente narrativa oral que, en síntesis, relata lo siguiente: En tiempos remotos, el mallku era dueño de todos los animales silvestres. Después cedió dos de ellos al hombre para su domesticación - la llama y la alpaca-. Y al hombre se transformó en su pastor. Pero el espíritu de la montaña necesitaba su propio pastor para su gran ganado silvestre. Entonces eligió al felino. Y este fue el pastor sobrenatural del espíritu de la montaña. Por ser pastor, simboliza al pastor-hombre. Y por ser sobrenatural, se vincula simbólicamente con el espíritu de la montaña y su ganado silvestre. En forma de gato montés, el felino se encarna en el sueño de un pastor, relatado en el siguiente texto de un tono de enfloramiento (canción de marcación de ganado): 
"¿Adónde partes Suimaya?

"Yo con el gato Suimaya sueño,

"Gato montés, gato.

"Suinave:

"Yo te veré en el sueño...

"De lejos eres pequeño.

"De cerca eres pequeño.

"Gato de sueño...".

2) Pájaro chullumpe: Vive y nada "en grandes lagunas y en lagunas pequeñas". Se dice que "es bueno para la suerte del pastor", para la multiplicación de su ganado. Se cree que es el ánima o alma de la llama y que, como tal, "vive" en la llama. Varios testimonios orales relatan que en tiempos remotos -asociados aparentemente a los períodos de caza-recolección y del origen de la domesticación- salía el hombre a cazar llamas para domesticarlas. Las laceaba llevándolas luego a su vivienda. Allí las amarraba a un poste para comenzar luego su domesticación. Pero, al día siguiente, encontraba en la punta del lazo solamente un pájaro chullumpe. Se creia que la llama tenía el poder de transformarse en pájaro chullumpe; y éste en llama. Haciendo uso de dichos poderes, eludía la domesticación. El chullumpe representa simbólicamente a la llama, con la cual comparte algunos atributos comunes: patas y cuello largos y los colores matizados de su plumaje.

3) Cóndor y águila: Se relacionan con los cuerpos celestes - sol, luna, estrellas y cruz del sur- por su vuelo alto y poderoso. Se da una relación metonímica del cóndor con la cruz del sur que, se cree, adorna su cabeza durante el vuelo alto. A ambos pájaros se les atribuye el poder de propiciar la buena suerte en reciprocidades, intercambios y transacciones comerciales. Una vez embalsamados, se les introduce billetes en sus respectivos picos.

4) Quirquincho o armadillo: Se relaciona metonímicamente con pachamama o la santa madre tierra, por vivir debajo de la tierra en cuevas que él mismo cava. Mientras el crecimiento de su pelaje es indicador de buena suerte, su pérdida es señal de suerte adversa. Los aymaras afirman que "trae suerte para vender, comprar y cambalachar". Una vez embalsamado, se florea como ganado, introduciéndole, además, billetes en su hocico.

5) Serpiente, sapo y lagarto: Son animales emblemáticos de Sereno -el espíritu del agua y de la música-. Y, por lo tanto, se asocian al agua subterránea --ojos de agua, vertientes andinas, aguas termales, etc.-. Representan simbólicamente a la fertilidad de la tierra, del ganado y de la especie humana. El verde de las aguas subterráneas suele ser su color simbólico. Su dueño guarda secretamente a cada uno de estos tres animales, vivos o disecados -sin embalsamar-, en cajitas de cartón. Se cree que favorecen el enriquecimiento de su dueño (véanse fotos 11 a 13). 


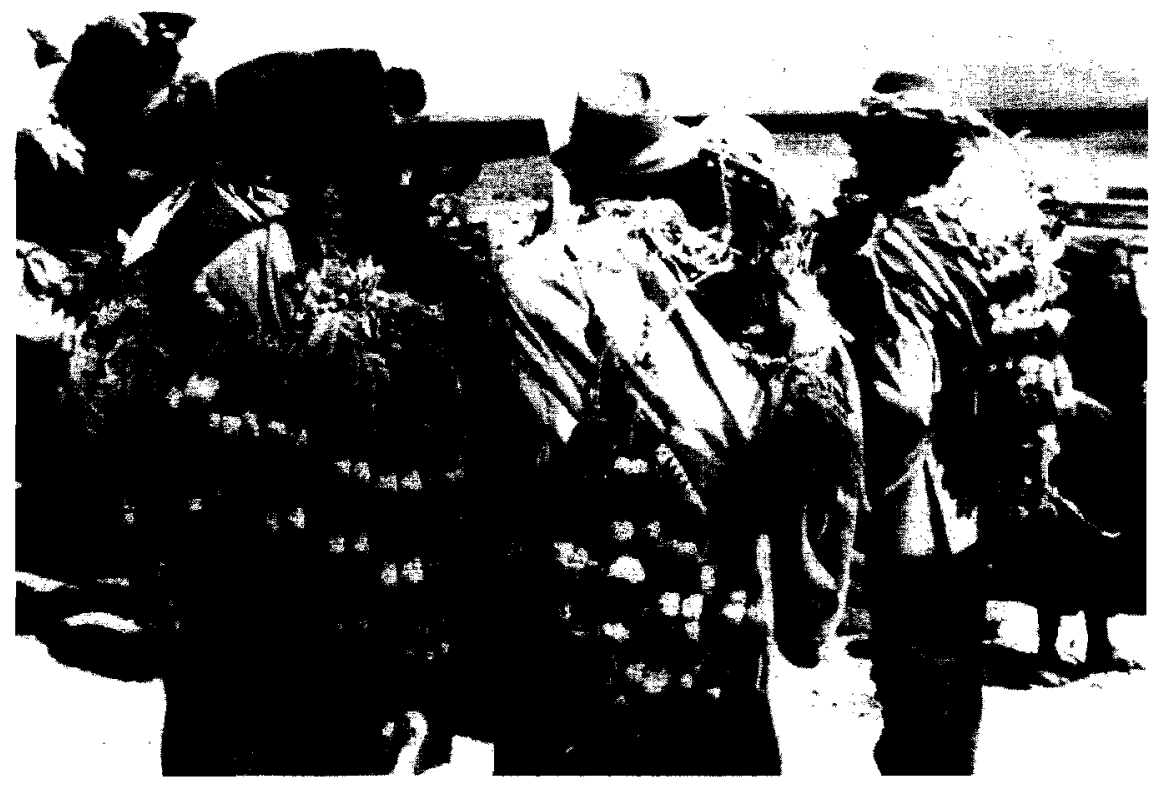

11. Culebrillas.

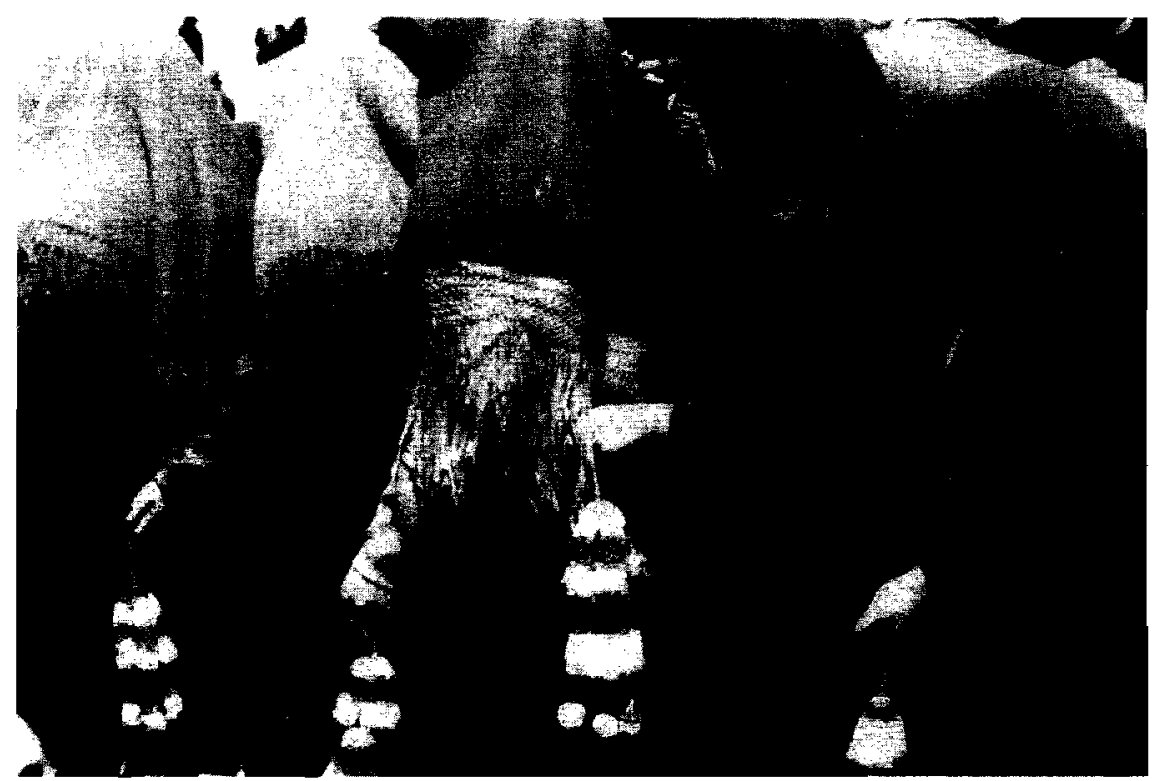

12. Culebrillas. 


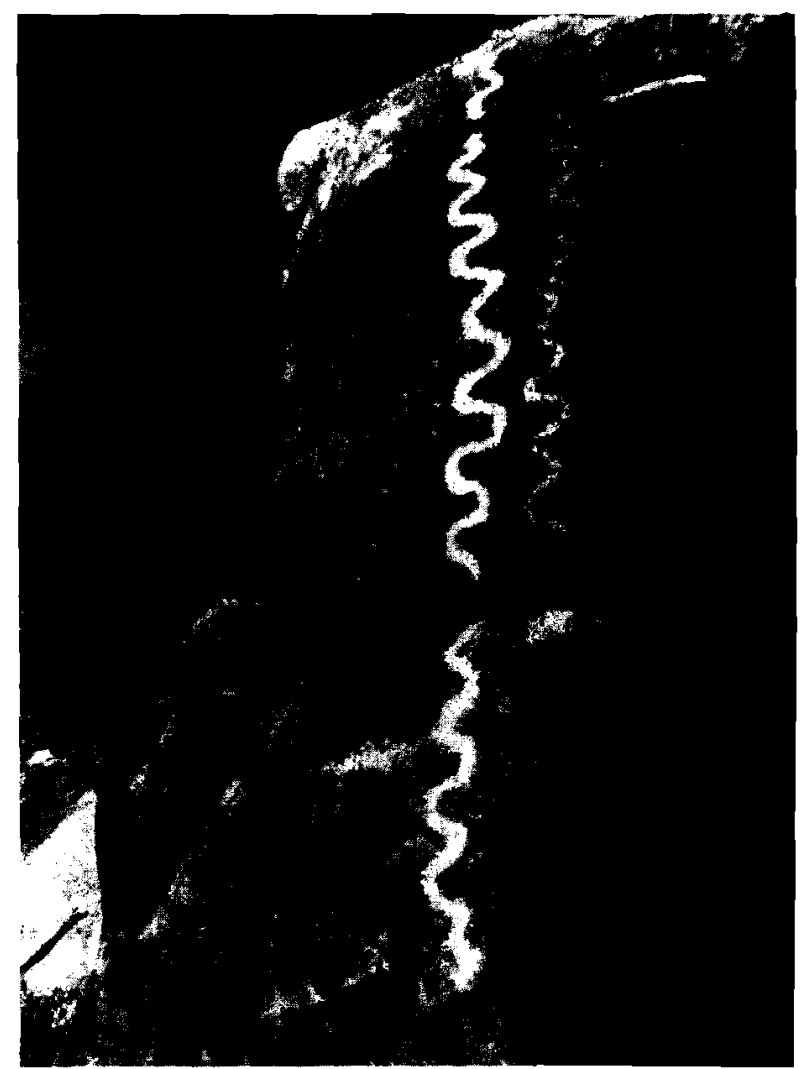

13. Culebra en petroglifo prehispano.

Según algunos informantes de mayor experiencia ritual, "estos animales sagrados son del tiempo de gentiles, tiempo en que ellos se volvían gente". Así, se cree que en un período prehispano remoto había hombres-cóndores, hombres-lagartos, hombres-quirquinchos, etc., los cuales aparecían, ya sea en su forma humana o animal, interactuando con los seres humanos. Varias narrativas, recogidas en los años recientes por la autora de este trabajo, se refieren a la interacción del hombre-animal con una mujer humana, con la cual hace vida común, se casa y procrea hijos. Uno de estos relatos narra las relaciones amorosas de una mujer con un hombre-cóndor. Otro narra las relaciones amorosas de una mujer con un hombre-quirquincho, un hombre-lagarto y un hombre-zorro; y los problemas para adjudicar paternidad a uno de los tres. En una sugerente canción ritual dedicada a un pájaro chullumpe hembra, se le invoca diciendo: "Mamá, hermana chullumpe: hoy día bailaremos". Todos estos contenidos apuntan hacia la creencia en un parentesco remoto que une al hombre y al animal. 
La reactualización ritual de las creencias en estos hombresanimales, evento tradicional que se desarrolla al final de la fiesta patronal de Santo Tomás en el pueblo Isluga, ha ocurrido cada año a fines del mes de diciembre. En dicha ocasión aparecen los achachi, actores rituales enmascarados que se asocian a los antepasados ápices del grupo étnico y, eventualmente, al período mítico de caza-recolección. Sus vestimentas se adornan con plumas de avestruz y de flamenco rosado - antiguos pájaros sagrados de los $k^{\prime}$ ollas--, y con colas de guanaco o vicuña, todos ellos animales andinos silvestres. Dichos actores rituales desarrollan una especie de antirritual, comunicándose mediante un lenguaje gutural y gestos grotescos, desplazándose con movimientos zoomorfos (véase foto 14).

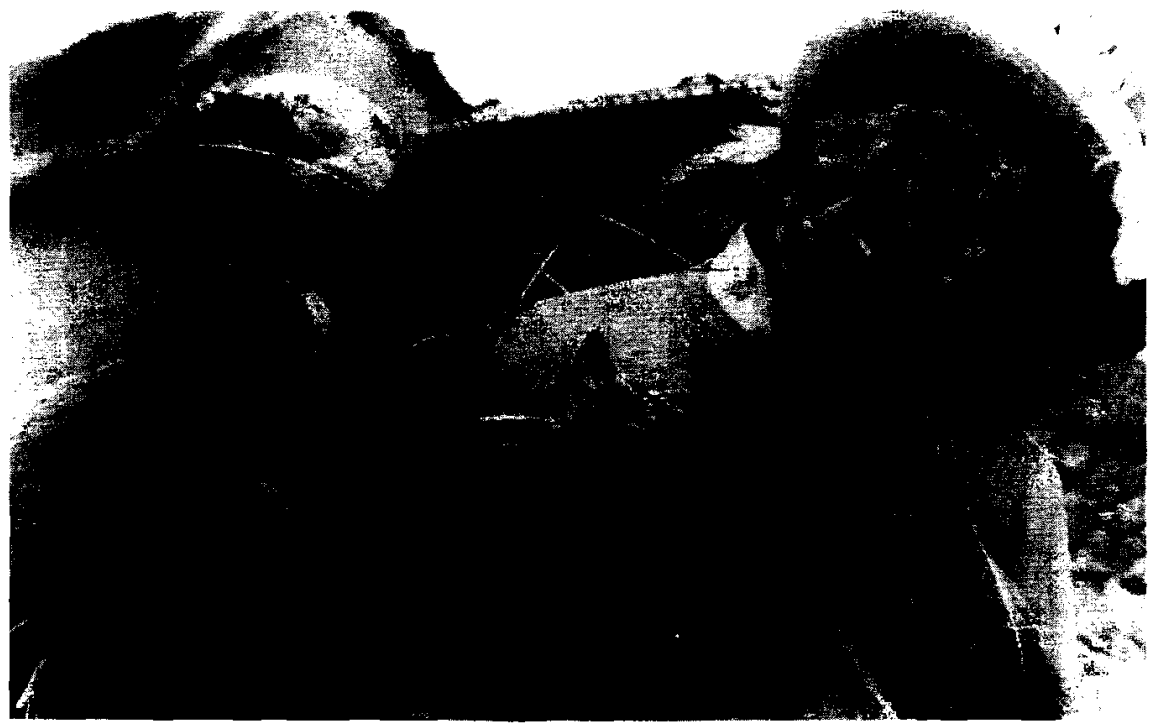

14. Achachi enmascarados.

\section{ConClusiones y Discusión}

Los resultados empíricos de esta investigación indican que:

1. El culto aymara a los animales sagrados emblemáticos en la comunidad altiplánica de Isluga posee aún plena vigencia en el contexto de los ritos de marcación de ganado, de carnaval, y de otros ritos privados y secretos, revelando la continuidad de los patrones cognitivo-simbólicos andinos que parecen remontarse a un pasado remoto.

2. Dichos animales sagrados forman parte de una etnotaxonomía zoológica que ordena la fauna altiplánica a partir de las categorías de los actores, permitiendo comprender las relaciones entre el hombre andino y el reino animal (Grebe, 1986, pp. 12-13 y 15). 
3. Los ocho animales sagrados emblemáticos de Isluga están asociados a tres funciones productivas básicas del mundo andino: pastoreo, agricultura y reciprocidad-intercambio, representándolas simbólicamente.

4. La permanencia de estas concepciones y de sus patrones cognitivosimbólicos contribuyen a reforzar la continuidad e identidad de la cultura andina regional, como también a la identificación e interpretación de significados simbólicos de mayor alcance para la comprensión de sus principios culturales dominantes.

5. Un variado corpus de creencias y tradiciones orales vincula a los animales sagrados con los espíritus de la montaña, hombres, astros, otros animales y elementos de la naturaleza.

6. Se destaca la creencia mítica acerca de la existencia remota de hombres-animales que solían aparecer, ya sea en su forma humana o animal, interactuando con los seres humanos. La reactualización ritual de estos seres míticos, asociados a los antepasados ápices del grupo étnico y al período de caza-recolección, se ha producido en eventos rituales del mes de diciembre en Isluga.

7. En las reactualizaciones rituales y sistema de creencias reaparecen patrones cognitivo-simbólicos explícitos o subyacentes ligados a principios culturales dominantes del mundo andino: la búsqueda del orden cósmico y de la fertilidad, expresados en la dualidad, las relaciones simétricas, la bifurcación sexual, la reciprocidad y redistribución.

En su estudio etnohistórico del antiguo totemismo andino, Latcham (pp. 55-87), influido por el pensamiento antropológico vigente en su época, aboga por la vinculación de las creencias y ritos relativos a los animales sagrados con los rasgos dominantes del totemismo. Por tanto, este autor adopta criterios coincidentes con los planteamientos clásicos de Frazer, Rivers, Durkheim, Robertson Smith, Radcliffe-Brown, Lienhardt y otros. (Véanse también las revisiones de Radcliffe-Brown, pp. 117-132, Evans-Pritchard, pp. 48-77, y Lévi-Strauss, pp. 9-28). En suma, de acuerdo a dichos criterios, los rasgos dominantes del totemismo son: a) la organización en clanes exógamos; b) la creencia en un parentesco entre clan y tótem; c) la atribución de nombres o de emblemas animales, vegetales o de objetos inanimados a los clanes; d) el culto religioso a los animales, plantas y objetos totémicos; e) la prohibición de matar y/o comer al tótem, los cuales no parecen ser rasgos generalizados.

Aunque varios de estos rasgos dominantes están presentes en el culto a los animales sagrados de Isluga, no existe allí la prohibición de matar y comer al animal sagrado, puesto que en dicha comunidad estos animales se matan principalmente para embalsamarlos.

No obstante, el problema de fondo reside en la discusión antropológica sobre la validez teórica y empírica del concepto mismo de totemismo (Mendelson, p. 127). Dichas discusiones llegan a su apogeo con Van Gennep. Pero es Goldenweiser (1910 y 1918) quien 
somete el concepto a una crítica sistemática, a partir de la cual "el lugar consagrado al problema totémico... no cesará de disminuir con el transcurso de los años" (Lévi-Strauss, p. 15). En lo sucesivo, decrece el interés por el tópico. Ya en 1912, Lowie (p. 41) comentaba que habría que considerar si el totemismo es una realidad cultural, o bien "fantasmas salidos de nuestros modos lógicos de clasificación". Por su parte, Boas (pp. 319-326) consideró al totemismo como una unidad artificial producida por el pensamiento del etnólogo. Por último, Lévi-Strauss (p. 151) concluye que la realidad del totemismo "se reduce a ser ejemplo particular de ciertos modos de reflexión... Su imagen es proyectada, no recibida; no toma su sustancia de fuera. Pues si la ilusión [totémica] cubre una parcela de verdad, ésta no se halla fuera de nosotros, sino en nosotros".

En consecuencia, concluimos que el culto a los animales sagrados emblemáticos de Isluga sugiere, más bien, un modo de pensamiento; una conexión muy especial entre el hombre, la naturaleza y lo sobrenatural; una instancia específica en las relaciones entre el hombre y los objetos de su ambiente natural, mediatizado por su sistema de creencias y pensamiento simbólico. Dicho culto altiplánico reproduce los principios dominantes del mundo andino: el ordenamiento cósmico tradicional se reactualiza en el ceremonial de la mesa, microcosmo del orden paradigmático andino expresado en círculos, simetrías y espejos; la idea central de fertilidad se manifiesta explícitamente en la propiciación de los espíritus de la montaña y tierra, quienes controlan la vida, reproducción y bienestar del reino vegetal y animal, de los cuales depende el hombre andino; la dualidad se expresa en la organización de las actividades ceremoniales, en las cuales imperan las divisiones binarias expresadas en los pares y relaciones simétricas; la bifurcación sexual está presente en el culto a la pareja macho-hembra de animales sagrados como también en el rito presidido por la pareja aymara: el pastor y su esposa; los principios andinos de reciprocidad y redistribución se manifiestan elocuentemente en los sacrificios y ofrendas al mallku y lo que se espera recibir de él como retribución, y también en la distribución de los alimentos rituales que se comparten equitativamente entre todos los participantes.

En la reactualización ritual de estos principios culturales dominantes se reproducen y refuerzan los patrones cognitivo-simbólicos de continuidad del mundo andino. En este sentido, podríamos considerar el culto a los animales sagrados emblemáticos de Isluga como una metáfora sociocultural plena de creatividad, fantasía e imaginación humana que revitaliza las matrices profundas de la cultura aymara.

\section{BIBLIOGRAFÍA}

Boas, Franz. "The Origin of Totemism". American Anthropologist, XVIII, 1916, pp. 319-326. 
Dillehay, Tom. Sobre la Interpretación del Simbolo del Jaguar. Valdivia, Universidad Austral, 1978 (inéd.).

Durkheim, Emile. The Elementary Forms of the Religious Life. Nueva York, The Free Press, 1965.

Evans-Pritchard, E.E. Theories of Primitive Religion. Oxford, Oxford University Press, 1965.

Frazer, J.G. The Golden Bough. Nueva York, Macmillan, 1958.

Goldenweiser, Alexander. "Totemism: An Analytical Study". Journal of American Folklore, XXIII, 1910, pp. 179-293.

Goldenweiser, Alexander. "Form and Content in Totemism". American Anthropologist, N.S., XX, 1918, pp. 230-295.

Grebe, M. Ester. Generative Models, Symbolic Structures and Acculturation in the Panpipe Music of the Aymara of Tarapaca, Chile. Belfast, The Queen's University of Belfast, Tesis Doctoral en Antropología Social, 1980, 2 vols.

Grebe, M. Ester. "Cosmovisión Aymara". Revista de Santiago I, 1981, pp. 61-79.

Grebe, M. Ester. "Etnozoología Andina: Concepciones e Interacciones del Hombre Andino con la Fauna Altiplánica". Scripta Ethnologica [Buenos Aires], X, 1986, pp. 7-18.

Latcham, Ricardo. "The Totemism of the Ancient Andean Peoples". Journal of the Royal Anthropological Institute of Great Britain and Ireland, LVII, 1927, pp. 55-87.

Lévi-Strauss, Claude. El Totemismo en la Actualidad. México, Fondo de Cultura Económica, 1965.

Lienhardt, Godfrey. "Primitive Religion". En Encyclopaedia Britannica, XIV, 1974, pp. 1040-1047.

Lowie, Robert H. "On the Principle of Convergence in Ethnology". Journal of American Folklore, XXV, 1912.

Mendelson, Michael. "The 'Uninvited Guest': Ancilla to Lévi-Strauss on Totemism and Primitive Thought". Edmund Leach ed., The Structural Study of Myth and Totemism (ASA Monographs, 5), Londres, Tavistock, 1967, pp. 119-139.

Radcliffe-Brown, A.R. "The Sociological Theory of Totemism". A.R. RadcliffeBrown, Structure and Function in Primitive Society, Nueva York, The Free Press, 1952, pp. 117-132.

Rivers, W.H.R. The History of Melanesian Society. Cambridge, Cambridge University Press, 1914, 2 vols.

Tschopik, Harry. The Aymara of Chucuito, Perú. Nueva York, Anthropological Papers of the American Museum of Natural History, 44, 2, 1951.

Smith, Robertson. The Religion of the Semites. Nueva York, Meridian Books (1889) 1965.

Van Gennep, A. L'Etat Actuel du Problème Totémique. París, Ernest Leroux, 1920. 